\title{
Investigating prevalence of musculoskeletal disorders among Iranian nurses: A systematic review and meta-analysis
}

\author{
Bayan Saberipour $^{\mathrm{a}}$, Saeed Ghanbari ${ }^{\mathrm{b}}$, Kourosh Zarea ${ }^{\mathrm{c}}$, Mahin Gheibizadeh ${ }^{\mathrm{c} * *}$, Maryam Zahedian ${ }^{\mathrm{d}}$ \\ a Student's Research Committee, Ahvaz Jundishapur University of Medical Sciences, Ahvaz, Iran \\ ${ }^{\mathbf{b}}$ Department of Biostatistics, School of Medicine, Shiraz University of Medical Sciences, Shiraz, Iran \\ ${ }^{c}$ Nursing Care Research Center in Chronic Diseases, Ahvaz Jundishapur University of Medical Sciences, Ahvaz, Iran \\ ${ }^{\mathrm{d}}$ School of Nursing and Midwifery, Ahvaz Jundishapur University of Medical Sciences, Ahvaz, Iran
}

\section{A R T I C L E I N F O}

\section{Keywords:}

Musculoskeletal disorders

Ergonomics

Nurses

\begin{abstract}
A B S T R A C T
Introduction: Musculoskeletal disorders are one of the most common and costly occupational injuries. Nursing profession, considering the nature of the work, is one of the occupations in hospital in which work-related musculoskeletal disorders are highly prevalent. This review study was conducted to determine the prevalence of musculoskeletal disorders among Iranian nurses.

Materials and methods: The present study was conducted on the basis of the PRISMA checklist for systematic review and meta-analysis. To access eligible articles, domestic and foreign databases such as Web of Science, Scopus, Science Direct, PUBMED, Magiran, SID, Medlib Irandoc, and the Google scholar search engine and keywords of musculoskeletal disorders, ergonomics, nurses, and Iran were used. In this review, two researchers reviewed the relevant articles published from 2000 to 2017. At first, 1349 papers were entered but finally, 33 eligible articles were analyzed. Data analysis was carried out using STATA software (ver. 11.5).

Findings: The results of the review of 33 eligible articles showed that the prevalence of musculoskeletal disorders and low back pain in nurses were 0.84 (95\% CI: 0.83-0.95) and 0.60 (95\% CI: 0.60-0.61) respectively.

Conclusion: The results of the previous studies revealed that the prevalence of musculoskeletal disorders, especially low back pain in nurses, is high. Therefore, planning and intervention should be performed to prevent and reduce musculoskeletal disorders in nurses.
\end{abstract}

\section{Introduction}

Musculoskeletal disorders which are referred to as permanent injury or permanent pain in the body structure, such as muscles, joints, tendons, ligaments, nerves, bones, and the circulatory system, ${ }^{1}$ are prevalent worldwide and are considered to be major occupational injuries in developed and developing countries ${ }^{2}, 3$.

Work-related skeletal-musculoskeletal disorders (WMSDs) are the most important common cause of lost work days, increased costs and human injuries and the main cause of disability. ${ }^{4,5}$ On the other hand, healthcare staffs are more likely to develop musculoskeletal disorders than workers in construction, mining and manufacturing industries. ${ }^{6,7}$ Among healthcare staffs, nurses who play an important role in healthcare organizations are the largest group at risk for musculoskeletal disorders. ${ }^{8}, 9$

The nursing profession, due to the nature of work, is among occupations in which WMSDs are highly prevalent. These disorders occur in various parts of the body, including the neck, shoulder, arm, wrist, and lower back, in which the back pain is most prevalent one. ${ }^{10,11}$ Several factors lead to musculoskeletal disorders in nurses, such as frequent lifting of heavy objects, ${ }^{12,13}$ moving the patients, ${ }^{2}$ inappropriate physical posture, ${ }^{14}$ fixed and constant posture of the neck, ${ }^{15}$ long standing, ${ }^{16}$ excessive rotations, ${ }^{14}$ psychological factors ${ }^{18}$ and work experience and body mass index (BMI), ${ }^{15}$ increasing working hours, ${ }^{16}$ increasing age and work experience. ${ }^{3}$ In a systematic and meta-analysis study aimed at assessing the relationship between psychological risk factors in the workplace and musculoskeletal disorders among nurses and nursing assistants Bernal et al., referred to psychological disorders as an important factor in increasing the incidence of low back pain and shoulder pain in the workplace. ${ }^{1}$

There are many foreign studies on the prevalence of musculoskeletal disorders among nurses. For example, Eunkwang Ryu et al. reported a prevalence rate of $70.8 \%$ for musculoskeletal disorders among nurses. ${ }^{18}$ Marina Nützi et al. in Switzerland and Sofia Backåberg ${ }^{19}$ in Sweden

\footnotetext{
* Corresponding author at: School of Nursing and Midwifery, Nursing Care Research Center in Chronic Diseases, Ahvaz Jundishapur University of Medical Sciences, Ahvaz, Iran.

E-mail address: gheibizadeh-m@ajums.ac.ir (M. Gheibizadeh).
} 


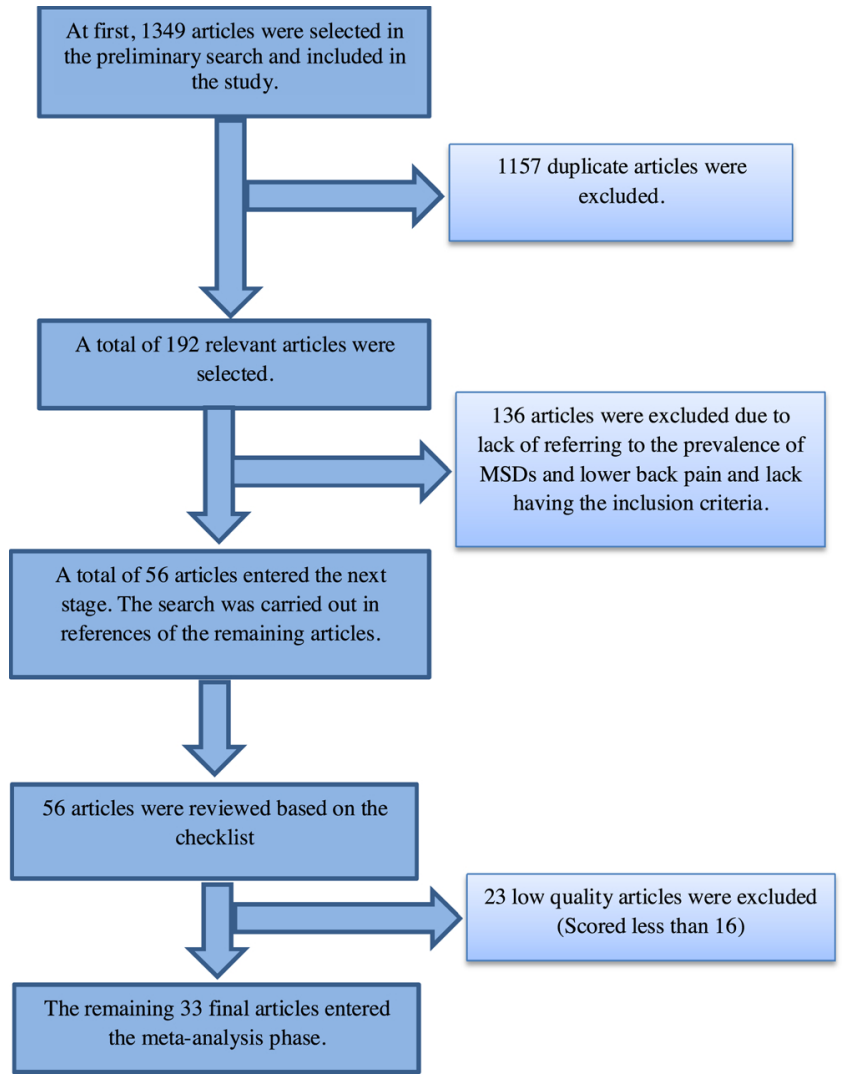

Flowchart 1. The inclusion stages of studies into systematic reviews.

reported a prevalence rate of $66 \%$ and $64 \%$ for the aforementioned disorders, respectively. ${ }^{20}$ Similarly, numerous studies have also been carried out across the country such as Chubineh et al in Shiraz, ${ }^{21} \mathrm{Ar}-$ salani et al. in Tehran ${ }^{3}$ and Imanzad et al. in Qom ${ }^{22}$ that respectively reported a prevalence rate of $84.4 \%, 88 \%$ and $47.5 \%$, for MSDs among studied nurses. Considering the importance of the issue and the impact of various factors on MSDs, it would be useful to reach a conclusion by reviewing all relevant documentations and presenting an overall estimate so that we can provide a solution to the nurses' problem. Therefore, the present study aimed to investigate the prevalence of MSDs among Iranian nurses using systematic review and meta-analysis.

\section{Materials and methods}

The present study is a systematic review and meta-analysis that is based on reporting system for systematic review and meta-analysis studies (PRISMA). ${ }^{23}$ To avoid bias in the study, the search, selection of studies, qualitative evaluation and data extraction were carried out independently by two researchers. In case of disagreement between the two researchers, the third researcher was referred and the final agreement was carried out in the form of a general discussion.

The findings of this study are based on studies conducted within Iran. The Persian and English related documentations were used from national electronic databases, SID, Iranmedex, Magiran and international electronic databases, including PubMed, Scopus, Web of Science, Science Direct, Online Library Wiley, Springer, and the Google Scholar search engine. Searching was carried out using keywords of Musculoskeletal disorders, Ergonomics, Nurses and Iran, and all possible conjunctions of words using AND, OR operators for the English databases.
Table 1

Characteristics of studies entered into the meta-analysis.

\begin{tabular}{|c|c|c|c|c|}
\hline Author & year & Place & Sample size & instrument \\
\hline Gholami $^{28}$ & 2016 & Tehran & 325 & $\begin{array}{l}\text { Body Map } \\
\text { Questionnaire }\end{array}$ \\
\hline Abedini 29 & 2012 & Shiraz & 400 & Nordic Questionnaire \\
\hline Azma ${ }^{9}$ & 2014 & Tehran & 144 & $\begin{array}{l}\text { Cornell } \\
\text { Musculoskeletal }\end{array}$ \\
\hline Taheri ${ }^{30}$ & 2014 & Esfahan & 247 & Nordic Questionnaire \\
\hline Shafiezadeh ${ }^{31}$ & 2011 & Ahvaz & 161 & Nordic Questionnaire \\
\hline Sharif Niya ${ }^{32}$ & 2010 & Amol & 400 & Nordic Questionnaire \\
\hline Habibi ${ }^{33}$ & 2015 & Esfahan & 250 & Nordic Questionnaire \\
\hline Habibi ${ }^{34}$ & 2015 & Esfahan & 200 & Nordic Questionnaire \\
\hline $\begin{array}{l}\text { Zarrin } \\
\qquad \begin{array}{l}\text { Ghabaee } \\
35\end{array}\end{array}$ & 2016 & Sari & 940 & Nordic Questionnaire \\
\hline Raeisi ${ }^{36}$ & 2013 & Tehran & 447 & Nordic Questionnaire \\
\hline Rokni $^{16}$ & 2015 & $\begin{array}{l}\text { Ghaemshahr } \\
\text { And Sari }\end{array}$ & 110 & Nordic Questionnaire \\
\hline Rahimi $^{37}$ & 2015 & Hamedan & 180 & back pain scale \\
\hline Dehdashti ${ }^{38}$ & 2015 & Damghan & 48 & Nordic Questionnaire \\
\hline Dadarkhah ${ }^{39}$ & 2013 & Army Hospital & 200 & Nordic Questionnaire \\
\hline Choobin $^{21}$ & 2007 & Shiraz & 642 & Nordic Questionnaire \\
\hline Khoshbakht ${ }^{40}$ & 2011 & Rasht & 91 & REBA tool \\
\hline Barzideh $^{17}$ & 2013 & Shiraz & 385 & Nordic Questionnaire \\
\hline Imanzad $^{22}$ & 2013 & Ghom & 264 & Nordic Questionnaire \\
\hline Mehdipour ${ }^{41}$ & 2012 & Ghazvin & 54 & Nordic Questionnaire \\
\hline Rezai $^{42}$ & 2014 & Tehran & 1246 & $\begin{array}{l}\text { questions about LBP } \\
\text { and its risk factors }\end{array}$ \\
\hline Choobin 43 & 2010 & Shiraz & 375 & Nordic Questionnaire \\
\hline Bandpei 44 & 2006 & North Of Iran & 1226 & $\begin{array}{l}\text { Self-made } \\
\text { questionnaire }\end{array}$ \\
\hline Farahabadi ${ }^{45}$ & 2016 & Ghom & 127 & Nordic Questionnaire \\
\hline Arsalani $^{3}$ & 2016 & Tehran & 520 & $\begin{array}{l}\text { working conditions and } \\
\text { MSDs }\end{array}$ \\
\hline Farokhi ${ }^{46}$ & 2016 & Esfahan & 250 & Nordic Questionnaire \\
\hline Nikpour 47 & 2009 & Tehran & 615 & Nordic Questionnaire \\
\hline Sadeghiyan 48 & 2005 & Shahroud & 245 & Nordic Questionnaire \\
\hline Asadi 49 & 2016 & Rasht & 350 & $\begin{array}{l}\text { information on the } \\
\text { status of skeletal pain }\end{array}$ \\
\hline Raeisi ${ }^{50}$ & 2011 & Tehran & 650 & Nordic Questionnaire \\
\hline Akbari ${ }^{51}$ & 2015 & Tehran & 220 & Nordic Questionnaire \\
\hline Taghinejad ${ }^{52}$ & 2016 & Ilam & 240 & Nordic Questionnaire \\
\hline Samaei ${ }^{53}$ & 2014 & Kerman & 243 & $\begin{array}{l}\text { List of MAPO and } \\
\text { PTAI }\end{array}$ \\
\hline Zamanian $^{54}$ & 2015 & Shiraz & 200 & Nordic Questionnaire \\
\hline
\end{tabular}

Table 2

The results of meta-analysis to combine the prevalence of Musculoskeletal Disorders in Nurses.

\begin{tabular}{|c|c|c|c|c|}
\hline \multirow{2}{*}{$\begin{array}{l}\text { Study } \\
\text { Gholami }^{28}\end{array}$} & \multirow{2}{*}{$\begin{array}{l}\text { ES } \\
0.783\end{array}$} & \multicolumn{2}{|c|}{ [95\% Conf. Interval] } & \multirow{2}{*}{$\begin{array}{l}\% \text { Weight } \\
5.38\end{array}$} \\
\hline & & 0.738 & 0.828 & \\
\hline Habibi $^{33}$ & 0.876 & 0.835 & 0.917 & 6.47 \\
\hline Abedini ${ }^{29}$ & 0.882 & 0.850 & 0.914 & 10.81 \\
\hline Shafiezadeh ${ }^{31}$ & 0.925 & 0.884 & 0.966 & 6.53 \\
\hline Khoshbakht ${ }^{40}$ & 0.777 & 0.691 & 0.863 & 1.48 \\
\hline Choobin ${ }^{21}$ & 0.844 & 0.816 & 0.872 & 13.72 \\
\hline Barzideh ${ }^{17}$ & 0.899 & 0.869 & 0.929 & 11.93 \\
\hline Imanzad $^{22}$ & 0.475 & 0.415 & 0.535 & 2.98 \\
\hline Farahabadi ${ }^{45}$ & 0.827 & 0.761 & 0.893 & 2.50 \\
\hline Arsalani ${ }^{3}$ & 0.880 & 0.852 & 0.908 & 13.85 \\
\hline Farokhi 46 & 0.876 & 0.835 & 0.917 & 6.47 \\
\hline Nikpour 47 & 0.798 & 0.766 & 0.830 & 10.73 \\
\hline Akbari ${ }^{51}$ & 0.795 & 0.742 & 0.848 & 3.80 \\
\hline Taghinejad ${ }^{52}$ & 0.719 & 0.662 & 0.776 & 3.34 \\
\hline I-V pooled ES & 0.842 & 0.832 & 0.853 & 100.00 \\
\hline
\end{tabular}




\begin{tabular}{|c|c|c|c|}
\hline Study & & & $\%$ \\
\hline ID & & ES $(95 \% \mathrm{Cl})$ & Weight \\
\hline gholami (2016) & & $0.78(0.74,0.83)$ & 5.38 \\
\hline habibi1 (2015) & & $0.88(0.84,0.92)$ & 6.47 \\
\hline abedini (2013) & & $0.88(0.85,0.91)$ & 10.81 \\
\hline Shafiezadeh (2011) & & $0.93(0.88,0.97)$ & 6.53 \\
\hline Khoshbakht (2011) & & $0.78(0.69,0.86)$ & 1.48 \\
\hline Choobin (2007) & 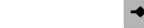 & $0.84(0.82,0.87)$ & 13.72 \\
\hline barzideh (2013) & & $0.90(0.87,0.93)$ & 11.93 \\
\hline Imanzad (2011) & $\rightarrow$ & $0.47(0.41,0.54)$ & 2.98 \\
\hline Farahabadi (2016) & & $0.83(0.76,0.89)$ & 2.50 \\
\hline Arsalani (2014) & & $0.88(0.85,0.91)$ & 13.85 \\
\hline Farokhi (2016) & & $0.88(0.84,0.92)$ & 6.47 \\
\hline Nikpour (2009) & $\rightarrow$ & $0.80(0.77,0.83)$ & 10.73 \\
\hline Akbari (2015) & $\rightarrow$ & $0.80(0.74,0.85)$ & 3.80 \\
\hline Taghinejad (2016) & $\rightarrow$ & $0.72(0.66,0.78)$ & 3.34 \\
\hline Overall (I-squared $=94.3 \%, p=0.000)$ & 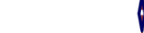 & $0.84(0.83,0.85)$ & 100.00 \\
\hline $\begin{array}{c}1 \\
-966\end{array}$ & & 56 & \\
\hline
\end{tabular}

Fig. 1. Forest plot of meta-analysis of the prevalence of Musculoskeletal Disorders in Nurses. Data are pooled prevalence's with 95\% CIs.

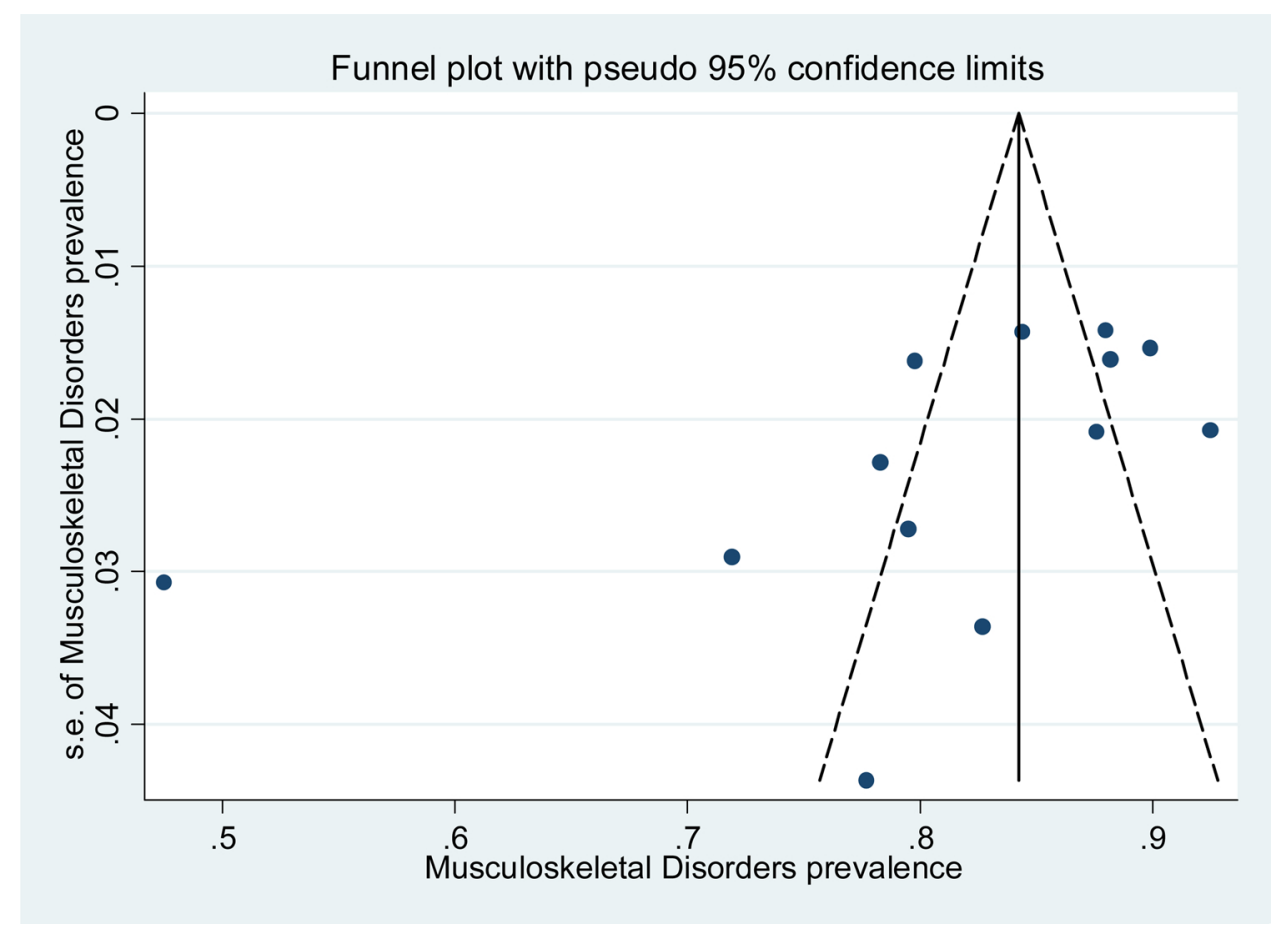

Fig. 2. Funnel plot of prevalence of musculoskeletal disorders. 
Table 3

The results of meta-analysis to combine the prevalence of low back pain in Nurses.

\begin{tabular}{|c|c|c|c|c|}
\hline \multirow{2}{*}{$\begin{array}{l}\text { Study } \\
\text { Gholami }^{28}\end{array}$} & \multirow{2}{*}{$\begin{array}{l}\text { ES } \\
0.591\end{array}$} & \multicolumn{2}{|c|}{ [95\% Conf. Interval] } & \multirow{2}{*}{$\begin{array}{l}\% \text { Weight } \\
2.53\end{array}$} \\
\hline & & 0.538 & 0.644 & \\
\hline Habibi $^{33}$ & 0.756 & 0.703 & 0.809 & 2.55 \\
\hline Azma ${ }^{9}$ & 0.458 & 0.377 & 0.540 & 1.09 \\
\hline Abedini 29 & 0.715 & 0.671 & 0.759 & 3.69 \\
\hline Taheri $^{30}$ & 0.761 & 0.708 & 0.814 & 2.55 \\
\hline Sharif Niya ${ }^{32}$ & 0.810 & 0.772 & 0.848 & 4.88 \\
\hline Habibi ${ }^{34}$ & 0.790 & 0.734 & 0.846 & 2.26 \\
\hline Zarrin Ghabaee ${ }^{35}$ & 0.609 & 0.578 & 0.640 & 7.42 \\
\hline Raeisi $^{36}$ & 0.568 & 0.522 & 0.614 & 3.42 \\
\hline Rokni $^{16}$ & 0.582 & 0.490 & 0.674 & 0.85 \\
\hline Rahimi $^{37}$ & 0.718 & 0.652 & 0.784 & 1.67 \\
\hline Dehdashti ${ }^{38}$ & 0.583 & 0.444 & 0.722 & 0.37 \\
\hline Dadarkhah ${ }^{39}$ & 0.478 & 0.409 & 0.547 & 1.51 \\
\hline Choobin 21 & 0.549 & 0.511 & 0.587 & 4.87 \\
\hline Barzideh ${ }^{17}$ & 0.618 & 0.569 & 0.667 & 3.06 \\
\hline Imanzad $^{22}$ & 0.749 & 0.696 & 0.801 & 2.64 \\
\hline Mehdipour ${ }^{41}$ & 0.722 & 0.603 & 0.841 & 0.51 \\
\hline Rezai 42 & 0.462 & 0.435 & 0.490 & 9.42 \\
\hline Choobin ${ }^{43}$ & 0.606 & 0.557 & 0.655 & 2.95 \\
\hline Bandpi ${ }^{44}$ & 0.620 & 0.593 & 0.647 & 9.77 \\
\hline Farahabadi 45 & 0.638 & 0.554 & 0.722 & 1.03 \\
\hline Arsalani ${ }^{3}$ & 0.653 & 0.612 & 0.694 & 4.31 \\
\hline Farokhi ${ }^{46}$ & 0.756 & 0.703 & 0.809 & 2.55 \\
\hline Nikpour ${ }^{47}$ & 0.541 & 0.502 & 0.580 & 4.65 \\
\hline Sadeghiyan ${ }^{48}$ & 0.499 & 0.436 & 0.562 & 1.84 \\
\hline Asadi 49 & 0.703 & 0.655 & 0.751 & 3.15 \\
\hline Raeisi ${ }^{50}$ & 0.590 & 0.552 & 0.628 & 5.05 \\
\hline Akbari ${ }^{51}$ & 0.691 & 0.630 & 0.752 & 1.94 \\
\hline Taghinejad ${ }^{52}$ & 0.400 & 0.338 & 0.462 & 1.88 \\
\hline Samaei ${ }^{53}$ & 0.695 & 0.637 & 0.753 & 2.15 \\
\hline Zamanian ${ }^{54}$ & 0.124 & 0.078 & 0.170 & 3.46 \\
\hline I-V pooled ES & 0.605 & 0.596 & 0.613 & 100.00 \\
\hline
\end{tabular}

The present research reviewed the studies that investigated the prevalence of musculoskeletal disorders in Iranian nurses working in hospitals during the period from April 2000 to April 2017 in Persian and English domestic and foreign language journals. Studies in which the samples were selected nonrandom, the data were inadequate, or the diagnosis of disorders was not based on laboratory diagnostic findings, were excluded.

After the initial screening of studies, screened studies were independently reviewed by two researchers using the standard STROBE checklist, which has 22 sections. ${ }^{24}$ The researchers evaluated selected articles from methodological aspects, including sampling method, variables measurement, statistical analysis and study objectives. Articles that scored at least 16 based on this checklist were selected for the meta-analysis stage. Any disagreement between the two researchers was investigated by the third person. The data of the final articles, which were included in the study process, were extracted from a preprepared checklist. The checklist includes the name of the author, year of study, place of study, sample size, mean age, prevalence of MSDs, lower back pain, neck pain, arm pain. Data obtained from the prevalence of MSDs among nurses were analyzed using STATA software (ver. 11.5). The significance level in all tests was considered as lower than 0.05 .

\section{Findings}

In the present systematic review, 1349 articles were identified, 1157 of which were deleted due to repeatability, 136 articles were deleted due to lack of full text and not having the inclusion criteria after a preliminary review. Then, 56 articles were selected and underwent full text review, which ultimately 33 articles were entered into meta-analysis (Flowchart 1).

The total number of participants in the finally selected studies was 11,995 . Table 1 shows the characteristics of each study. Of the 33 articles that were entered into the systematic review, 15 articles contained information on the prevalence of MSDs in general (Table 2). In addition to the confidence interval, the extent of the effect of each study on the final outcome and the overall prevalence rate were also presented in each study. Studies were heterogeneous (I-squared $=93.9 \%$, $\mathrm{Q}=230.80$, Tau-squared $=0.0063$ ), as indicated by the indicators of the homogeneity study. Therefore, the studies were weighted based on random-effects model so that we obtained the final prevalence rate of 0.842 (Fig. 1). Fig. 2 shows that there was publication bias exists between studies. However, the results of Egger test also confirm this finding ( $\mathrm{P}$-value $=0.042$ ). This means that lack of homogeneity between the studies may be due to the publication bias. In other words, all existing studies have not been used to assess the extent of the final prevalence rate.

The prevalence of low back pain in nurses was reported to be 0.613 (Table 3). In addition to the confidence interval, the extent of the effect of each study on the final outcome and the overall prevalence rate were also presented in each study. Studies are heterogeneous (I-squared $=$ $96.9 \%, Q=1014.65$, Tau-squared $=0.0189$ ), as indicated by the indicators of the homogeneity study. Therefore, the studies were weighted based on random-effects model so that we can obtain the final prevalence rate of 0.613 (Fig. 3). Fig. 4 shows that there is no publication bias between studies. Egger test results also confirm this finding $(\mathrm{P}$-value $=0.460)$. This means that lack of homogeneity between the studies may not be due to the publication bias. In other words, all existing studies have been used to assess the extent of the final prevalence rate and it is necessary to look for another cause for lack of heterogeneity between studies.

\section{Discussion}

The present systematic study aimed to investigate the prevalence of MSDs in Iranian nurses. A prevalence of $82 \%$ (95\% CI: 0.78\%-\%86) was determined for MSDs among Iranian nurses after reviewing 33 crosssectional studies with a sample size of 10,393 people. Parnu et al. reported in their study a MSDs prevalence rate of $31.8 \%(95 \% \mathrm{CI}$ : $24.1 \pm 39.4$ ) and $36.8 \%$ (95\% CI: $29.4-44.1 \%$ ) in the neck and shoulder regions, respectively. ${ }^{25}$

The results of current study showed that the prevalence of low back pain in nurses was 0.62 (95\% CI: 0.57-0.67). The results of a review study conducted by Mehrdad et al. on the musculoskeletal disorders and the onset of lower back pain in the medical staffs showed that the prevalence of low back pain in nurses and medical staffs was $0.58(95 \%$ CI: $0.58-0.59$ ) and $18.1 \%$ (CI: $0.17-18 \%) .{ }^{26}$ Also, in line with the present study, the results of Long et al.'s systematic study reported a prevalence rate of $35 \%$ for low back pain among nurses, midwives and physicians, ${ }^{27}$ which indicated a high prevalence rate for low back pain among nurses living in other countries. 


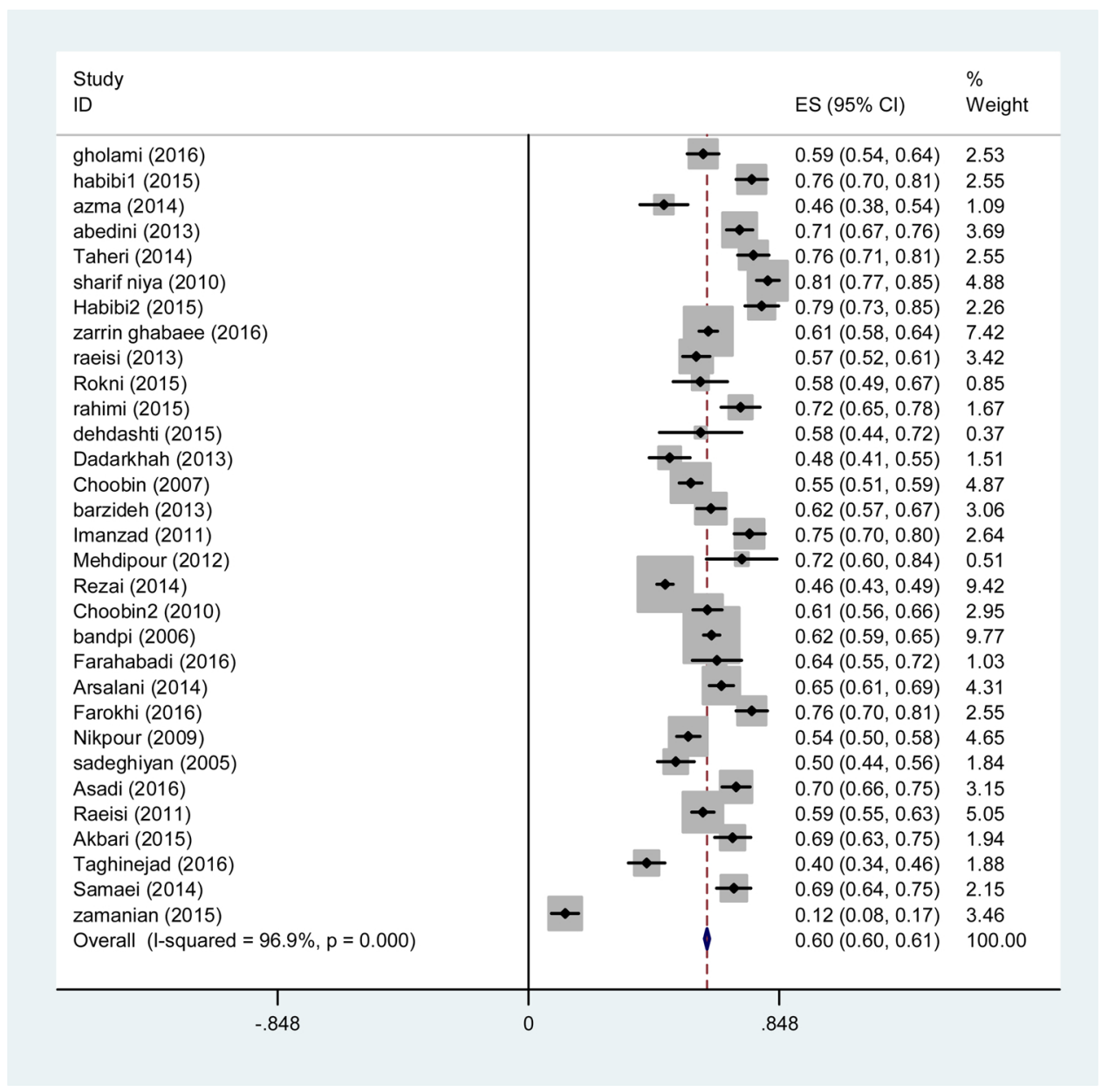

Fig. 3. Forest plot of meta-analysis of the prevalence of Back pain in Nurses. Data are pooled prevalence's with $95 \%$ CIs.

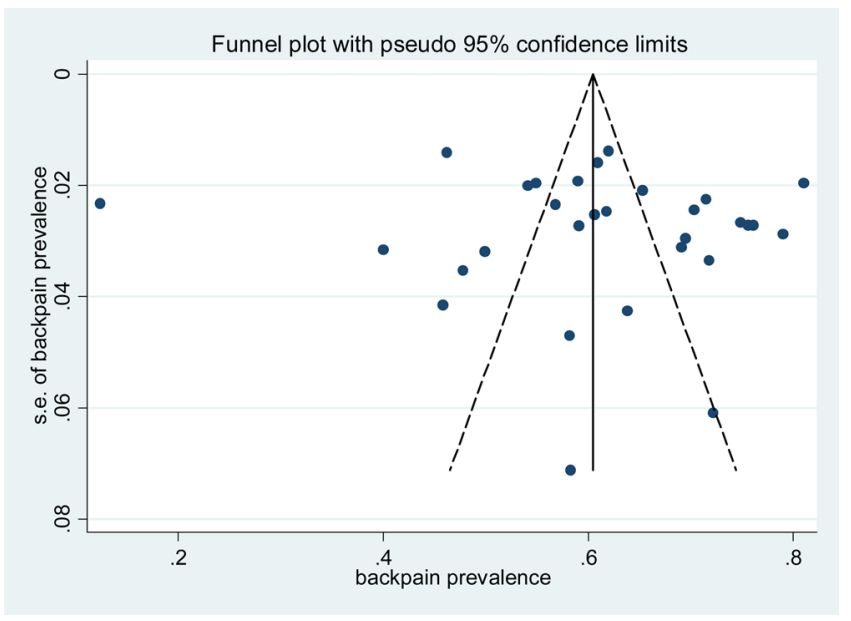

Fig. 4. Funnel plot of the back pain prevalence.

\section{Conclusion}

The results showed a high prevalence rate for MSDs, especially low back pain among Iranian nurses in the country. Therefore, it is essential to perform interventions at the macro level in order to perform ergonomics-related trainings and improve workplace equipment. It is also recommended that researchers conduct more systematic and metaanalytic researches focusing on the factors affecting nurses' MSDs.

\section{References}

1. Bernal D, Campos-Serna J, Tobias A, Vargas-Prada S, Benavides FG, Serra C. WorkRelated psychosocial risk factors and musculoskeletal disorders in hospital nurses and nursing aides: a systematic review and meta-analysis. Int J Nurs Stud. 2015;52(2):635-648.

2. Harcombe H, Herbison GP, Mcbride D, Derrett S. Musculoskeletal disorders among nurses compared with two other occupational groups. Occup Med (Chic Ill). 2014;64(8):601-607.

3. Arsalani N, Fallahi-Khoshknab M, Josephson M, Lagerstrom M. Musculoskeletal disorders and working conditions among iranian nursing personnel. Int J Occup Saf Ergon. 2014;20(4):671-680.

4. Bruno R, Da Costa PT. Risk factors for work-related musculoskeletal disorders: A systematic review of recent longitudinal studies. Am J Ind Med. 2010;53(March (3)):285.

5. David G, Woods V, Li G, Buckle P. The development of the quick exposure check (QEC) for assessing exposure to risk factors for workrelated musculoskeletal disorders. Appl Ergon. 2008;39(1):57-69.

6. Daraiseh N, Cronin S, Davis L, Shell R, Karwowski W. Low back Symptoms among hospital nurses, associations to individual factors and pain in multiple body regions. Int $J$ Ind Ergon. 2010;40(1):19-24.

7. Riksen W. The prevalence of musculoskeletal pain in Norwegian nurses' aides. Int Arch Occup Environ Health. 2003;76(8):625-630.

8. Szeto GP, Law KY, Lee E, Lau T, Chan SY, Law SW. Multifaceted ergonomic intervention programme for community nurses: pilot study. J Adv Nurs. 2010;66:1022-1034.

9. Azma K, Hosseini A, Safarian MH, Abedi M. Evaluation of the relationship between musculoskeletal discomforts and occupational stressors among nurses. N Am J Med Sci. 2015;7(7):322-327.

10. Reed LF, Battistutta D, Young J, Newman B. Prevalence and risk factors for foot and ankle musculoskeletal disorders experienced by nurses. BMC Musculoskelet Disord. 2014;15:196.

11. Yip Y. A study of work stress, patient handling activities and the risk of low back pain among nurses in Hong Kong. Journal of Advanced. Nursing. 2001;36(6):794-804.

12. Yu Wenzhou, Yu Ignatius T, Li Zhimin, et al. Work-related injuries and musculoskeletal disorders among factory workers in a major city of china. Accid Anal Prev. 2012;48(Sep):457-463. 
13. Azizpour Y, Delpisheh A, Maghsoodi Moghadam R. Ergonomic evaluation of job performance within the staff of the nursing and the operating room by reba technique. J Urmia Nurs Midwifery Fac. 2015;13(1):75-83.

14. Eftekhar Sadat B, Babaei A, Amidfar N, Jedari Eslami M. Prevalence And Risk Factors For Low Back Pain In Nursing Staffs Of Tabriz Hospitals In 1387. J Urmia Nurs Midwifery Fac. 2013;11(9):659-666 In Persian.

15. Mottaghi M, Basiri Moghadam M, Rohani Z, Basiri Moghadam K, Irani H. The survey of prevalence of vertebral column pain and some related factors in nurses employed in Gonabad hospitals. Horizon Med Sci. 2011;17(3):51-57.

16. Rokni M, Abadi MH, Saremi M, Mir Mohammadi MT. Prevalence of musculoskeletal disorders in nurses and its relationship with the knowledge of ergonomic and environmental factors. J Gorgan Univ Med Sci. 2016;18(1):128-132 In Persian.

17. Barzideh M, Choobineh A, Tabatabaei SH. Job stress dimensions and their relationship to musculoskeletal disorders in nurses. Int J Healthc Inf Syst Inform. 2013;8(7):1365-1375.

18. Ryu E, Ye B, Yi Y, Kim J. Risk factors of musculoskeletal symptoms in university hospital nurses. Ann Occup Environ Med. 2014;26:47.

19. Nützi M, Koch P, Baur H, Elfering A. Work-family conflict, task interruptions, and influence at work predict musculoskeletal pain in operating room nurses. Saf Health Work. 2015;6(4):329-337.

20. Backåberg S, Rask M, Brunt D, Gummesson C. Impact of musculoskeletal symptoms on general physical activity during nursing education. Nurse Educ Pract. 2014;14(4):385-390.

21. Choobineh A, Rajaeefard AR, Neghab M. Perceived demands and musculoskeletal disorders among hospital nurses. Hakim Health Sys Res. 2007;10(2):70-75.

22. Imanzad M, Gharlipour Z, Kohpaie A, Mohebi S, Arsang Gang S, Sayyarpour M, et al. Behavioral factors related to musculoskeletal disorders in nurses based on theory of planned behavior. Adv Nurs Midwifery. 2013;23(81):1-12.

23. Moher D, Liberati A, Tetzlaff J, Altman DG. Preferred reporting items for systematic reviews and metaanalyses: the PRISMA statement. Int J Surg. 2010:8(5):336-341.

24. Von Elm E, Altman DG, Egger M, Pocock SJ, Gøtzsche PC, Vandenbroucke JP, et al. The strengthening the reporting of observational studies in epidemiology (STROBE) statement: guidelines for reporting observational studies. Lancet. 2007;370(9596):1453-1457.

25. Parno A, Poursadeghiyan M, Omidi L, Parno M, Sayehmiri K, Sayehmiri F. The prevalence of work-related musculoskeletal disorders in the upper extremity: a systematic review and meta-analysis. J Saf Promot Inj Prev. 2016;4(1):9-18.

26. Mehrdad R, Sadat Shams-Hosseini N, Aghdaei S, Yousefian Mina. Prevalence of low back pain in health care workers and comparison with other occupational categories in Iran: a systematic review. Iran J Med Sci. 2016;41(6):467-478.

27. Long MH, Bogossian FE, Johnston V. The prevalence of work-related neck, shoulder, and upper back musculoskeletal disorders among midwives, nurses, and physicians: a systematic review. Workplace Health Saf. 2013;61(5):223-229.

28. Gholami M, Kavousi A, Saremi M. Identification and prioritization of the factors associated with musculoskeletal disorders in nurses at a specialized hospital. $J$ Ergon. 2016;4(2):44-51.

29. Abedini R, Choobineh Ar, Hasanzadeh J. Musculoskeletal disorders related to patient transfer in hospital nursing personnel. Health System Research. 2012;8(3):385-396.

30. Taheri MR, Habibi E, Hasanzadeh A, Mahdavi Rad M. Relative Stress Index (RSI): macroergonomics risk assessment of jobs in textile industry. Int J Healthc Inf Syst Inform. 2014;10(4):775-785

31. Shafizadeh KR. Prevalence of musculoskeletal disorders among paramedics working in a large hospital in Ahwaz, Southwestern Iran in 2010. Int J Occup Environ Med. 2011;2(3):157-165

32. Sharif Nia SH, Haghdoost AA, Hajihosseini F, Hojjati H. Relationship between the musculoskeletal disorders with the ergonomic factors in nurses. Koomesh. 2011;12(4):372-378.

33. Habibi E, Farrokhi E, Mansourian M. Assessment of nurses' patient transfer technique with dino method and compare it with MAPO method in estimation musculoskeletal disorders risk. J Prev Med. 2016;2(4):50-57.

34. Habibi E, Aghanasab M, Mohamadzadeh M, Farokhi E, Kohnavard B, Mohamadifard A. Use of the movement and assistance of hospital patients index for risk assessment of musculoskeletal disorders in hospital wards in Isfahan. Iran $J$ Health Syst Res. 2016;12(3):284-291.

35. Nasiry Zarrin Ghabaee D, Haresabadi M, Bagheri Nesami M, Talebpour Amiri F Work-related musculoskeletal disorders and their relationships with the quality of life in nurses. J Ergon. 2016;4(1):39-46.

36. Raeisi S, Hosseini M, Attarchi MS, Golabadi M, Rezaei MS, Namvar M. The association between job type and ward of service of nursing personnel and prevalence of musculoskeletal disorders. RJMS. 2013;20(108):1-10.

37. Rahimi A, Vazini H, Alhani F, Anoosheh M. Relationship between low back pain with quality of life, depression, anxiety and stress among emergency medical technicians. Trauma Mon. 2015;20(2):E18686.

38. Dehdashti A, Mahjoubi Z, Salarinia A. Impact of nurse's work related body postures on their musculoskeletal disorders. Koomesh. 2015;16(3):338-346.

39. Dadarkhah A, Azema K, Abedi M. Prevalence of musculoskeletal pains among nursing staff in AJA hospitals Tehran. EBNESINA- J Med. 2013;15(3):10-17.

40. Khoshbakht M, Baghaie Lakeh M, Hasavari F, Kazemnejad Leili E, Blourchian M. Evaluation of body posture ergonomyic during work in intensive care units nurses in teaching hospitals of guilan university of medical sciences in rasht city in 2010. $J$ Holist Nurs Midwifery. 2011;21(1):22-29.

41. MehdiPour HA, Habibi R, Rastak S, Westi M, Esmail Tayfa MA, Ilka M. Study of prevalence of musculoskeletal disorders in nurses working in operative part of hospitals rajaee and social security of Qazvin in 2012. Edrak. 2013;8(32):43-50.

42. Rezaee M, Ghasemi M. Prevalence of low back pain among nurses: predisposing factors and role of work place violence. Trauma Mon. 2014;19(4):9-14.

43. Choobineh A, Movahed M, Tabatabaie SH, Kumashiro M. Perceived demands and musculoskeletal disorders in operating room nurses of Shiraz city hospitals. Ind Health. 2010;48(1):74-84.

44. Mohseni-Bandpei MA, Fakhri M, Bagheri-Nesami M, Ahmad-Shirvani M, Khalilian AR, Shayesteh-Azar M. Occupational back pain in Iranian nurses: an epidemiological Study. Br J Nurs. 2006;15(17):914-917.

45. Farahabadi M, Aliakbarzade Arani Z, Chavoshizade SA, Barati A. Investigation of factors affecting musculoskeletal disorders among hospital emergency nurses of Qom university of medical sciences. Iran. Qom Univ Med Sci J. 2016;10(8):54-61.

46. Farrokhi E, Habibi E, Mansourian M. Risk assessment of musculoskeletal disorders related to patient transfer tasks using the direct nurse observation instrument method. Jundishapur J Helath Sci. 2016;8(4):E35936.

47. Nikpour S, Nooritajer M, Haghani H, Ravandi A. Musculoskeletal disorders among nurses in teaching hospitals affiliated to iran university of medical sciences and health services. IJN. 2009;22(60):8-18.

48. Sadeghian F, Kalalian Moghaddam H, Javanmard M, Khosravi A, Adelnia S. An epidemiological survey of low back pain and its relationship with occupational and personal factors among nursing personnel at hospitals of shahrood faculty of Medical Sciences. Iran South Med J. 2005;8(1):75-82.

49. Asadi P, Monsef Kasmaei V, Zia Ziabari SM, Zohrevandi B. The prevalence of low back pain among nurses working in poursina hospital in Rasht, Iran. $J$ Emerg Pract Trauma. 2016;2(1):11-15 In Persian.

50. Raeisi S, Namvar M, Golabadi M, Attarchi M. Combined effects of physical demands and shift working on low back disorders among nursing personnel. Int J Occup Saf Ergon. 2014;20(1):159-166

51. Akbari H, Akbari H, Bagheri Hossein Abadi M, Gholami Fesharaki M, Ghasemi M, et al. Assessing the risk of manual handling of patients and its relationship with the prevalence of musculoskeletal disorders among nursing staff: performance evaluation of the MAPO And PTAI methods. Iran Red Crescent Med J. 2017;19(2):E39860.

52. Taghinejad H, Azadi A, Suhrabi Z, Sayedinia M. Musculoskeletal disorders and their related risk factors among iranian nurses. Biotechnol Health Sci. 2016;3(1):E34473.

53. Samaei S, Hasheminejad N, Bagheri Hosseinabadi M, Zolala F. Comparison of risk assessment methods related to the patient's transfer and its relationship with prevalence of low back pain among hospital nursing personnel. Iran Occup Health J. 2016;13(1):58-68 In Persian.

54. Zamanian Z, Norouzi F, Esfandiari Z, Rahgosai M, Hasan F, Kohnavard B. Assessment of the prevalence of musculoskeletal disorders in nurses. Armaghane Danesh. 2017;21(10):976-986 In Persian. 